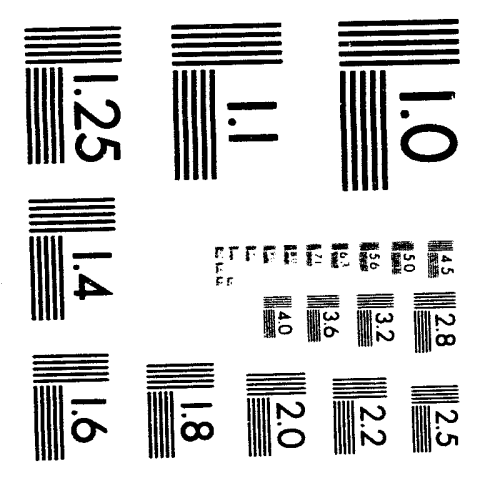



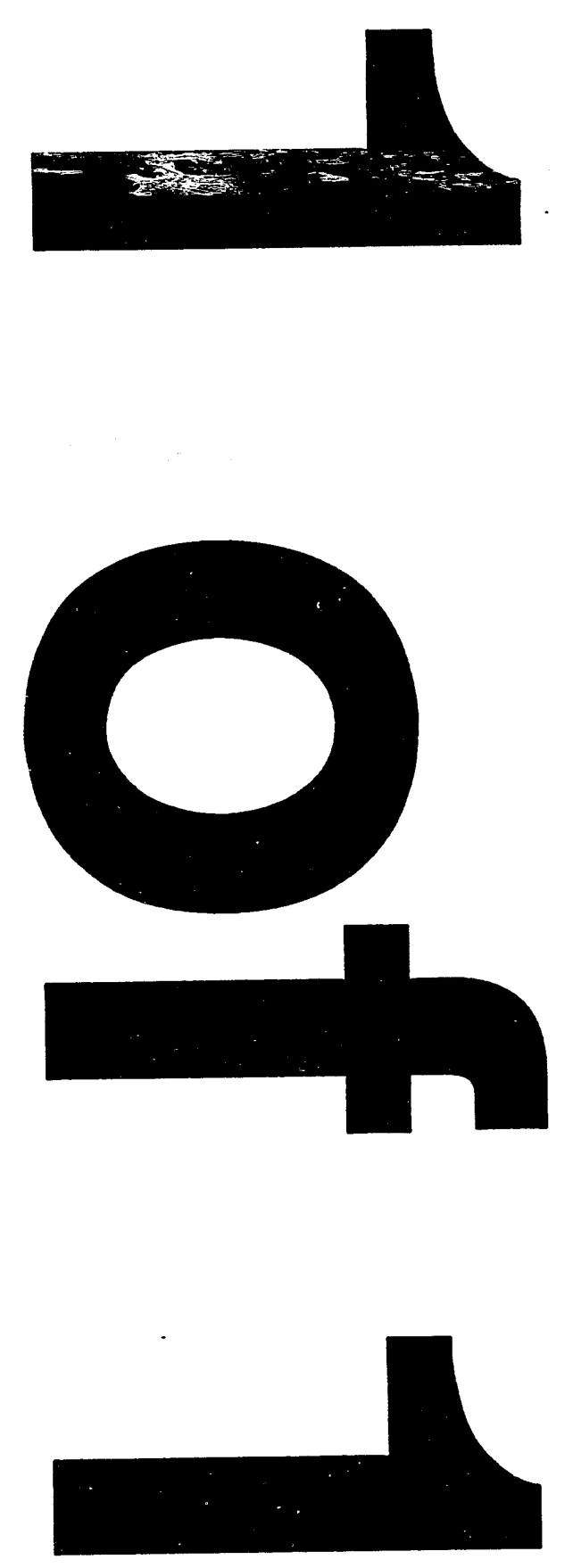
UCRL-ID-113831

\section{TART Calculations of Neutron Attenuation and Neutron-induced Photons on 5\% and 20\% Borated Polyethylene Slabs}

C. R. Wuest

April 20, 1993

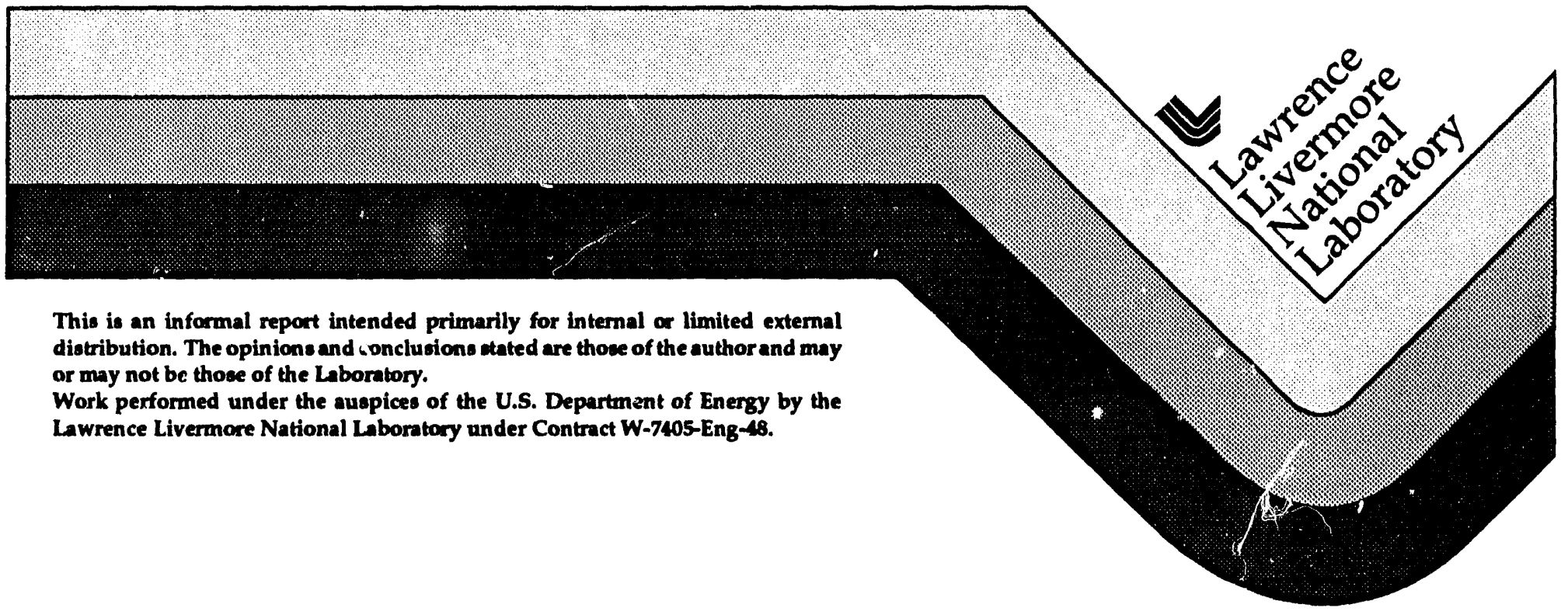




\section{DISCLAIMER}

This document was prepared as an account of work sponsored by an agency of the United States Government. Neither the United States Government nor the University of California nor any of their employees, makes any warranty, express or implied, or assumes any legal liability or responsibility for the accuracy, completeness, or usefulness of any information, apparatus, product, or process disclosed, or represents that its use would not infringe privately owned rights. Reference herein to any specific commercial products, process, or service by trade name, trademark, manufacturer, or otherwise, does not necessarily constitute or imply its endorsement, recommendation, or favoring by the United States Government or the University of California. The views and opinions of authors expressed herein do not necessarily state or reflect those of the United States Government or the University of California, and shall not be used for advertising or product endorsement purposes.

This report has been reproduced directly from the best available copy.

A vailable to $D O E$ and $D O E$ contractors from the Office of Scientific and Technical Information

P.O. Box 62, Oak Ridge, TN 37831

Prices available from (615) 576-8401, FTS 626-8401

A vailable to the public from the

National Technical Information Service

U.S. Department of Commerce

5285 Port Royal Rd.,

Springfield, VA 22161 
GEM TN-92-172

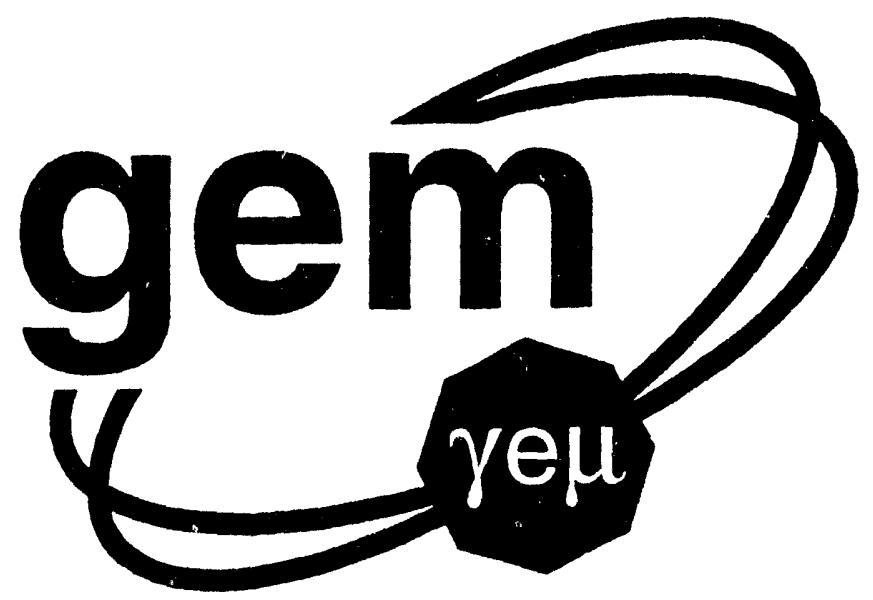

\title{
TART Calculations of Neutron Attenuation and Neutron-induced Photons on 5\% and $20 \%$ Borated Polyethylene Slabs
}

\author{
Craig R. Wuest \\ Lawrence Livermore National Laboratory
}

August 28, 1992

Abstract:

The coupled neutron/photon transport code TART has been used to calculate the attenuation of neutrons and the production of induced photons for neutrons incidents on $5 \%$ and $20 \%$ borated polyethylene slabs. The neutron attenuation lengths are found to be $2.4 \mathrm{~cm}$ and $2.9 \mathrm{~cm}$ for $5 \%$ and $20 \%$ borated polyethylene, respectively. 


\title{
TART Calculations of Neutron Attenuation and Neutron-induced Photons on 5\% and 20\% Borated Polyethylene Slabs
}

\author{
Craig R. Wuest
}

Lawrence Livermore National Laboratory

August 28, 1992

\begin{abstract}
The coupled neutron/photon transport code TART has been used to calculate the attenuation of neutrons and the production of induced photons for neutrons incident on $5 \%$ and $20 \%$ borated polyethylene slabs. The neutron attenuation lengths are found to be $2.4 \mathrm{~cm}$ and $2.9 \mathrm{~cm}$ for $5 \%$ and $20 \%$ borated polyethylene, respectively.
\end{abstract}

\section{Introduction}

The coupled neutron/photon transport Monte Carlo transport code TART $^{1}$ has been used to examine the effects of neutron shielding thicknesses for neutron attenuation and neutron-induced photons. Slabs of borated polyethylene were modeled with cylindrical geometry. Slabs $100 \mathrm{~cm}$ in radius and variable thickness from 1 to $20 \mathrm{~cm}$ were studied. In addition, two different mixtures of borated polyethylene were modeled. These mixtures were provided by Reactor Experiments, Inc. ${ }^{2}$ and are listed in Table I.

200,000 neutrons histories were generated for each calculation. Neutrons were incident along the axis of the cylindrical slabs in a beam of zero radius. The neutrons were sampled from an energy spectra provided by $L$. Waters for neutrons emitted from a model calorimeter. Figure 1 shows the neutron spectrum.

\section{Results}

\section{A. 5\% Borated Polyethylene}

Figure 2 shows the results of calculations for $5 \%$ borated polyethylene of thicknesses from $1-20 \mathrm{~cm}$. The figure shows the percent of neutrons and neutron-induced photons transmitted and reflected from the slabs as a function of thickness. The percentage is calculated with respect to the number of incident source neutrons and is integrated over all energies. A fit to the curve for neutrons transmitted gives an attenuation length of 2.94 $\mathrm{cm}$. Figures 3 and 4 show the photon and neutron energy spectra for both reflected and transmitted photons and neutrons. 


\section{B. $20 \%$ Borated Polyethylene}

Similar calculations were performed for the case of $20 \%$ borated polyethylene. Figure 5 shows the percent of neutrons and photons reflected and transmitted from slabs of various thicknesses. From Figure 5 the neutron attenuation length is calculated to be $2.4 \mathrm{~cm}$. Figures 6 and 7 show the photon and neutron energy spectra, respectively.

\section{Discussion}

In general, borated polyethylene is seen to reduce the amount of transmitted neutrons in an exponential fashion as a function of thickness. On the other hand, transmitted and reflected photons and reflected neutrons tend to approach constant values for slab thicknesses greater than about $5 \mathrm{~cm}$.

Surprisingly there is little difference between the $5 \%$ and $20 \%$ mixtures of borated polyethylene. This is presumably because of the decreased moderating of neutrons in the $20 \%$ mixture. There is a difference in the energy spectra of neutrons transmitted and reflected for the two mixtures, with the $20 \%$ mixture attenuating more of the low energy neutrons below about $100 \mathrm{eV}$. The reduction is about a factor of 10 between 10 and 100 $\mathrm{eV}$ and about a factor of 100 below $10 \mathrm{eV}$. There is little difference in the neutron-induced photon energy spectra.

\section{Conclusions}

These calculations show that the effectiveness of neutron attenuation is a complicated function of the amount of boron loading in the shielding material. There appear to be competing effects of neutron moderation provided by carbon and hydrogen, and neutron capture provided by boron. These calculations will be continued for other mixtures (10\% and 15\%) of borated polyethylene as well as boron mixtures in non-flammable binders.

\section{References:}

1. J. Kimlinger, N. Monson, and E. Plechaty, "TartNP, A Coupled Neutron-Photon Monte Carlo Transport Code," UCRL-50400 vol.14, 1976.

2. P. Lizak, faxed communication, Reactor Experiments, Inc., 1275 Hammerwood Ave., Sunnyvaie, CA 94089, (408) 745-6770. 
Table I: $\quad$ Borated Polyethylene Mixtures as provided by Reference (2) numbers are given as weight fractions

Element $\quad 5 \%$ Borated Polyethylene $20 \%$ Borated Polyethylene

$\mathrm{H}$

C

$11 \mathrm{~B}$

$10 \mathrm{~B}$

$\mathrm{Si}$

$\mathrm{O}$

Al

$\mathrm{Mn}$

$\mathrm{Fe}$
0.116

0.612

0.040

0.010

N/A

0.222

N/A

N/A

N/A
0.105

0.680

0.150

0.050

0.0068

0.005

0.0003

0.0001

0.0025 
Figure 1

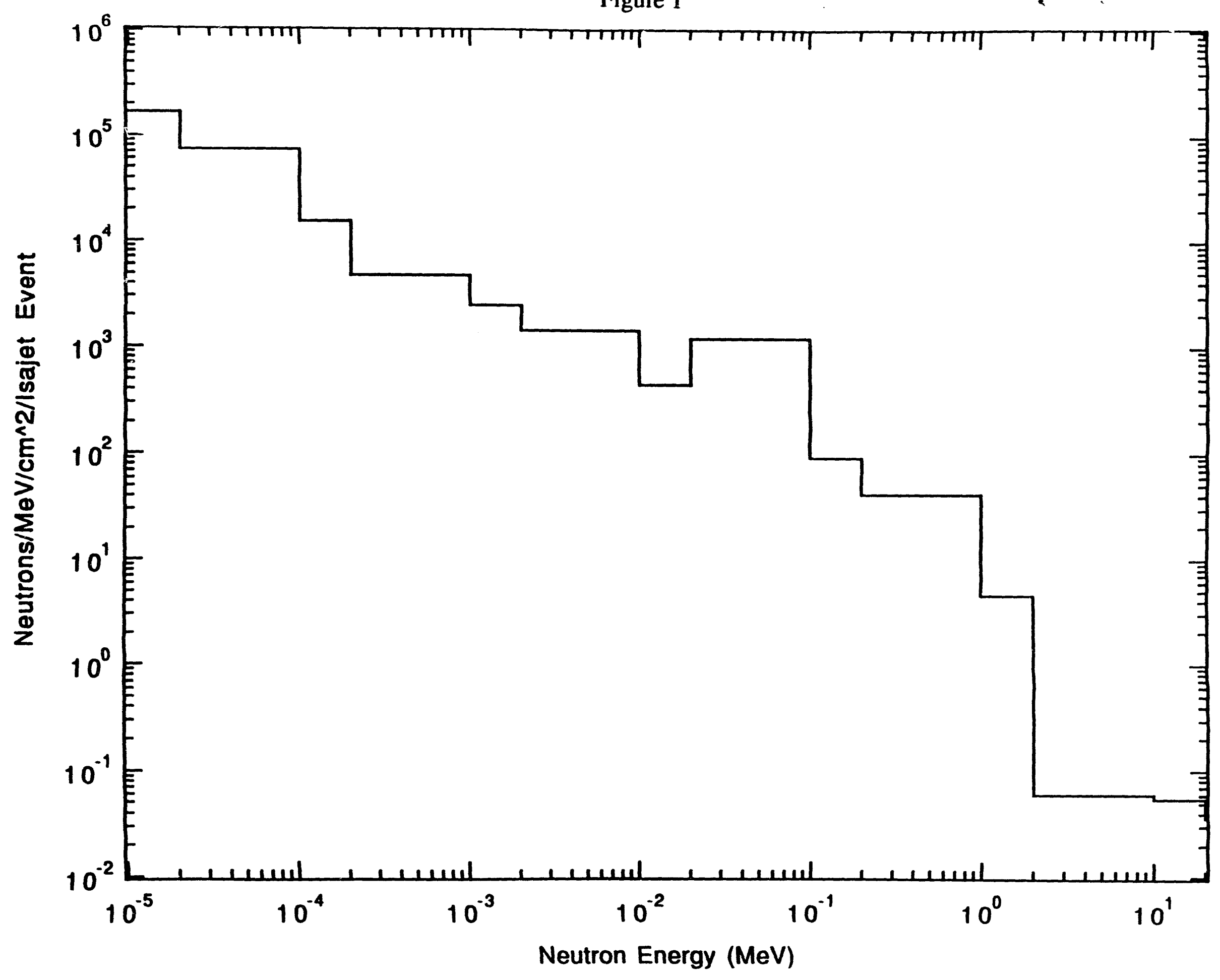


1. iguie $\angle$

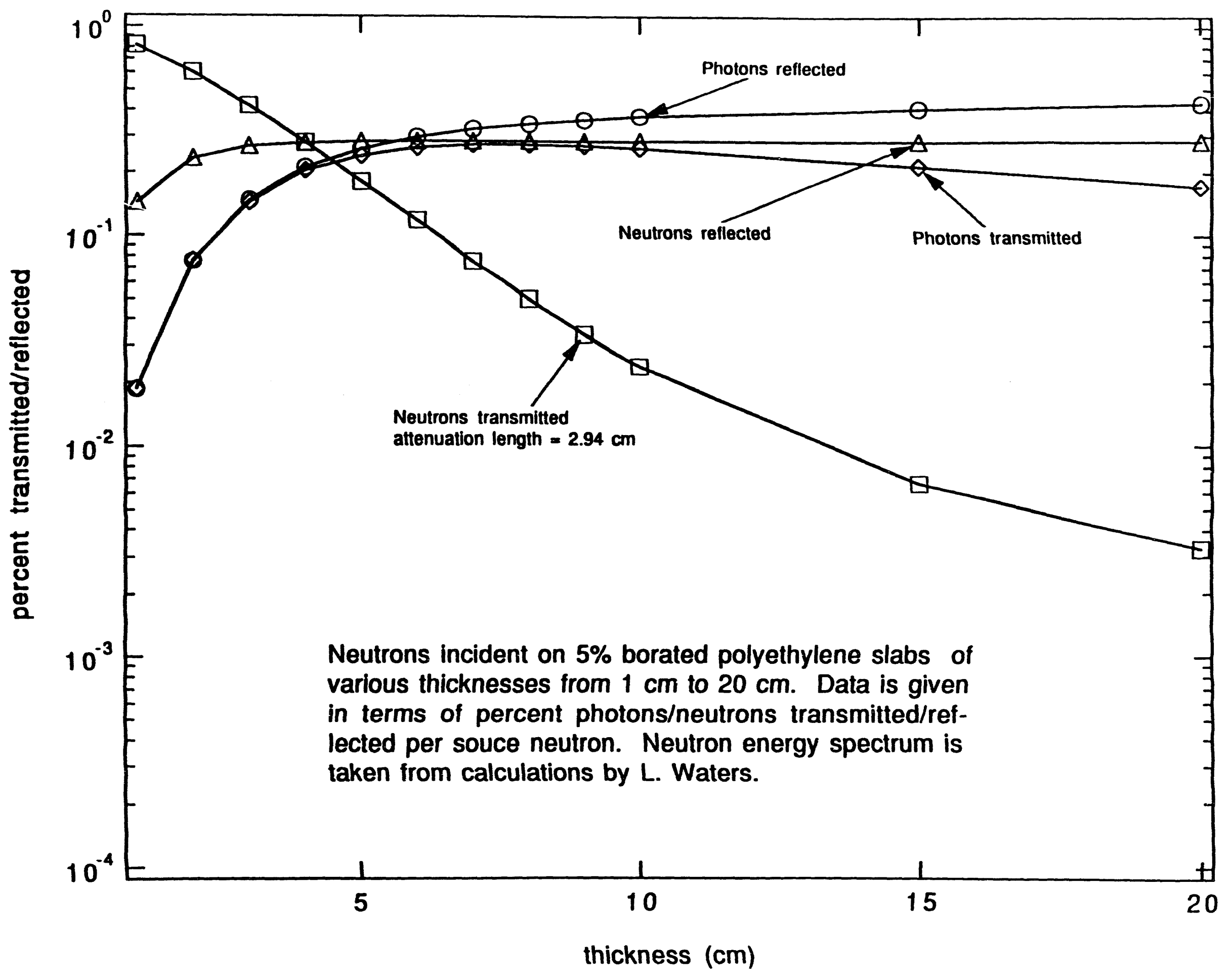




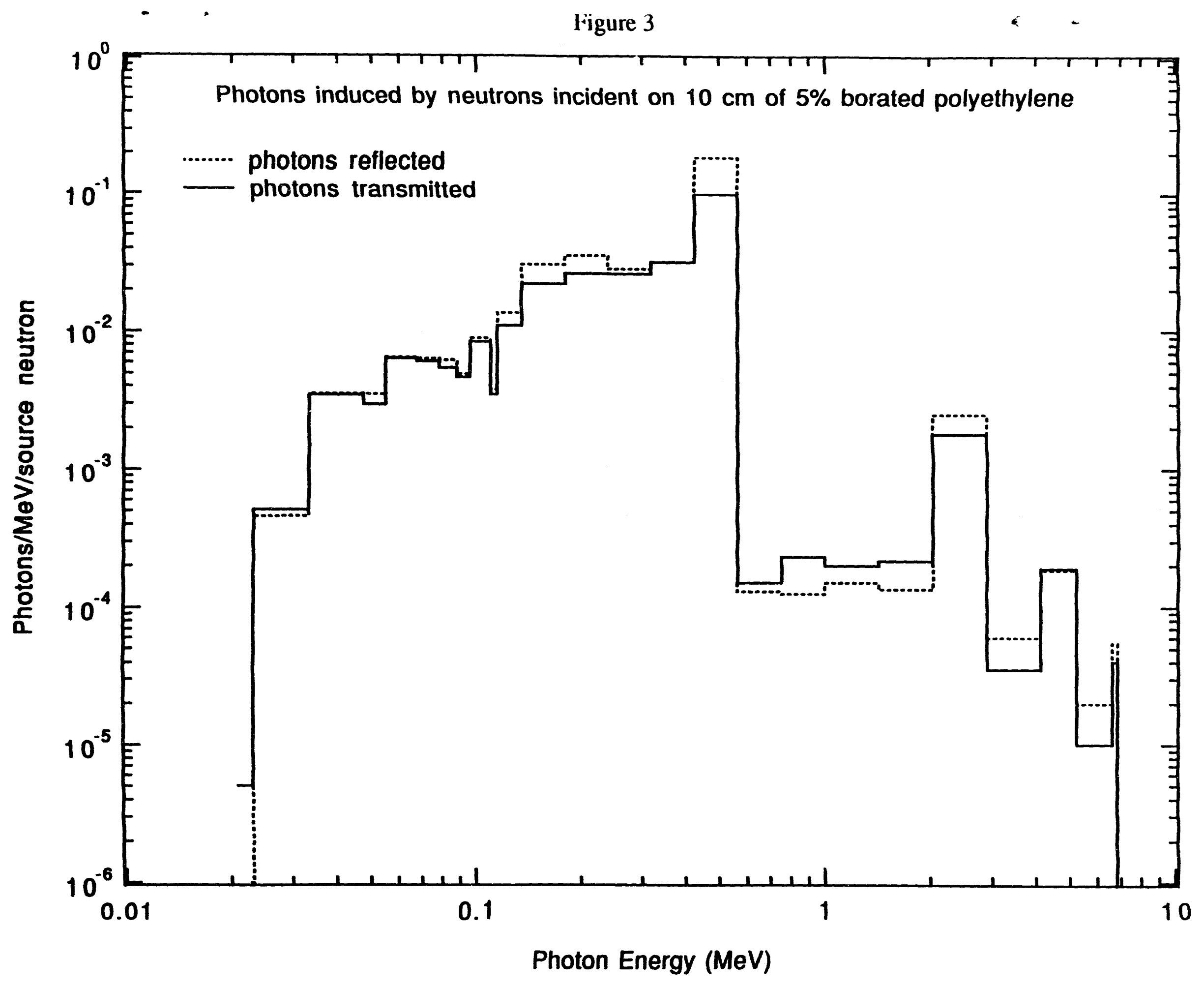


Figure 4

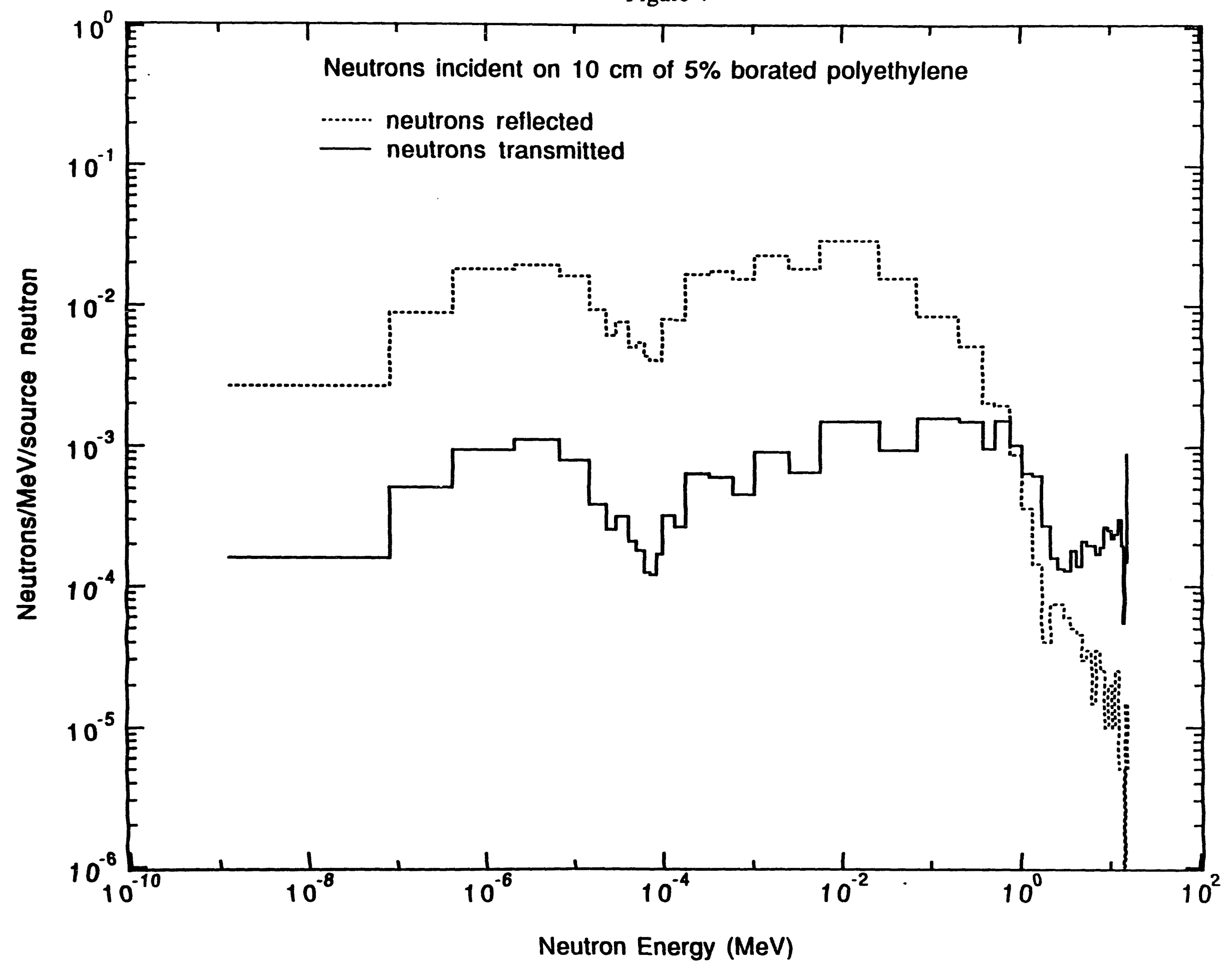




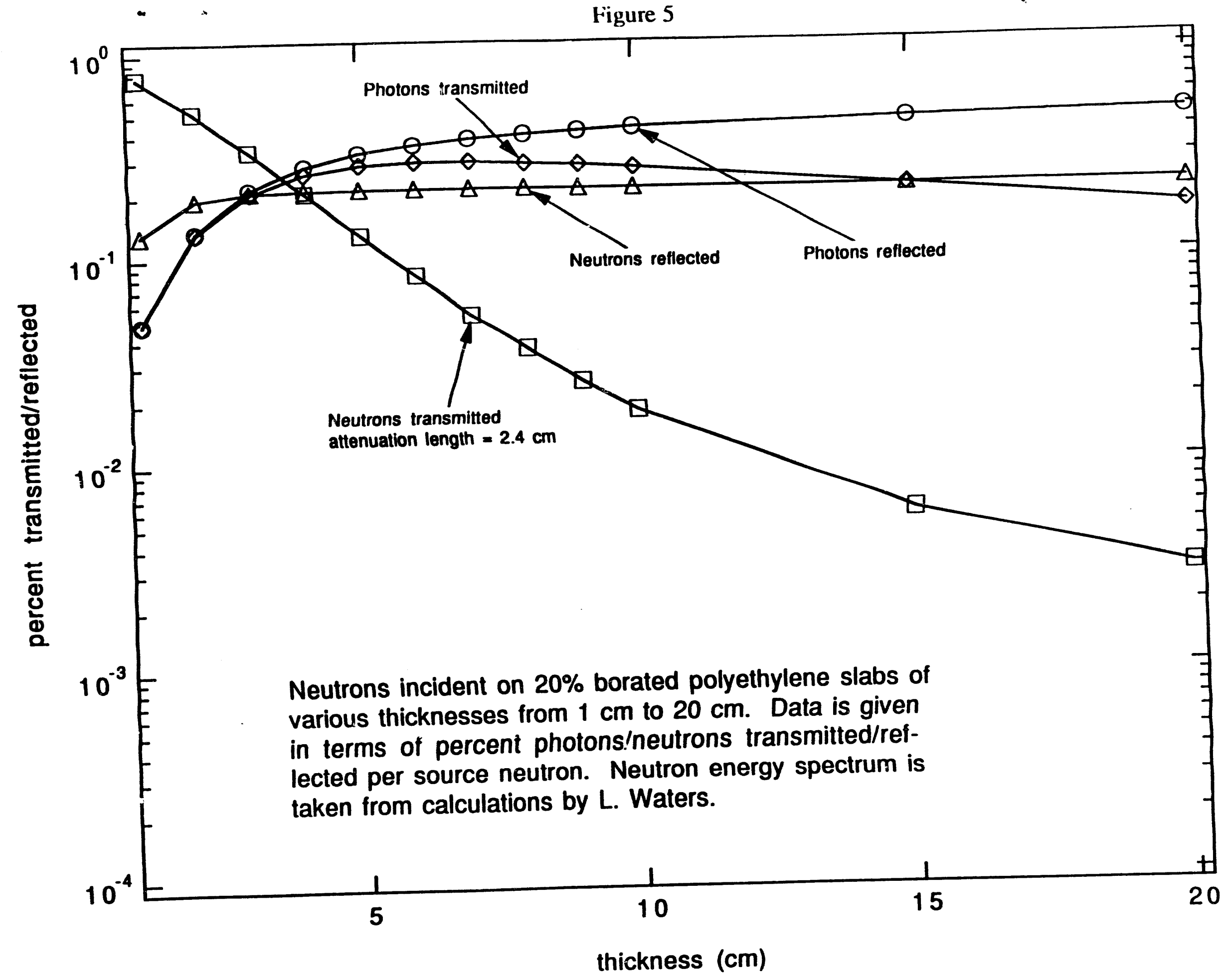


Figure 6

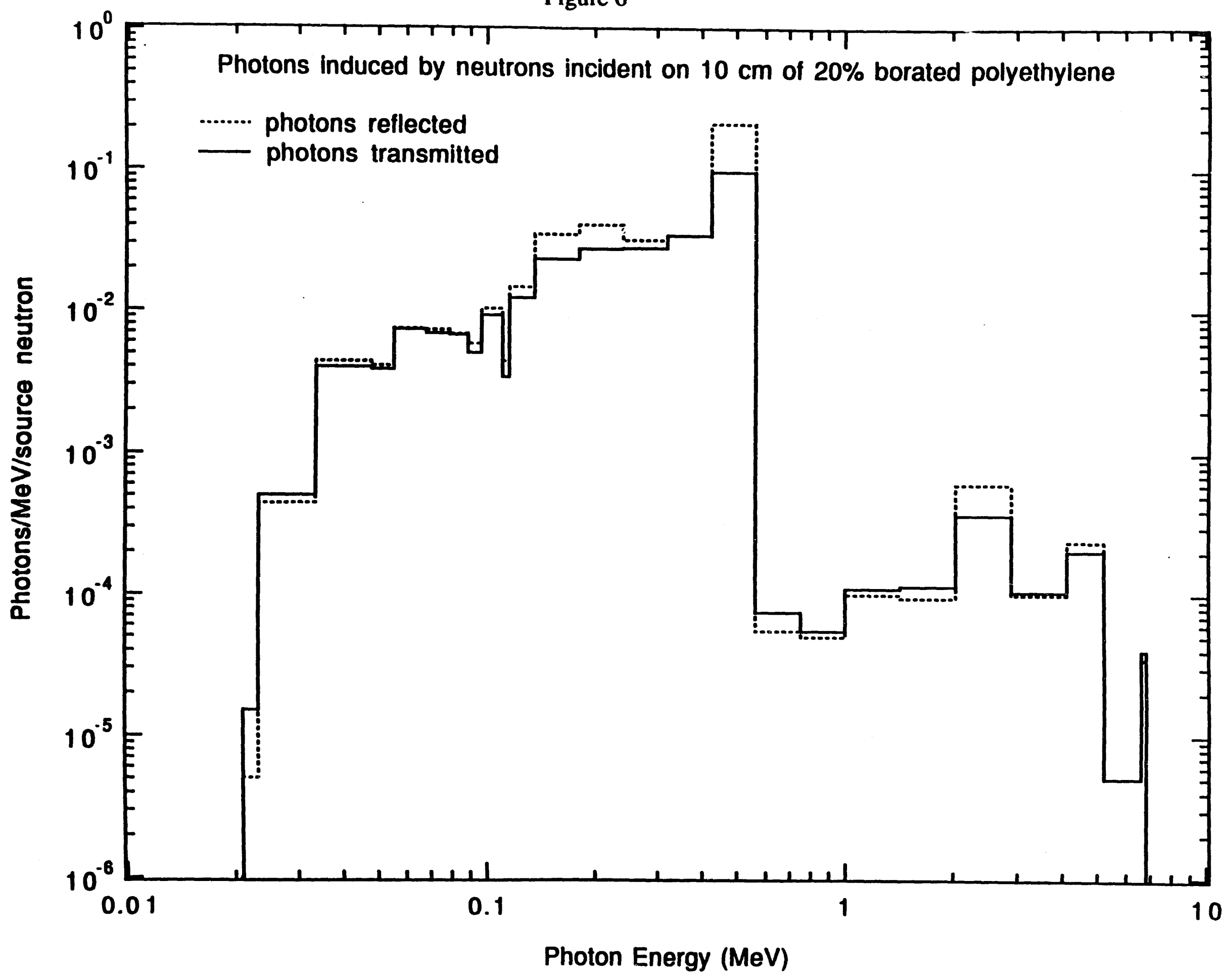




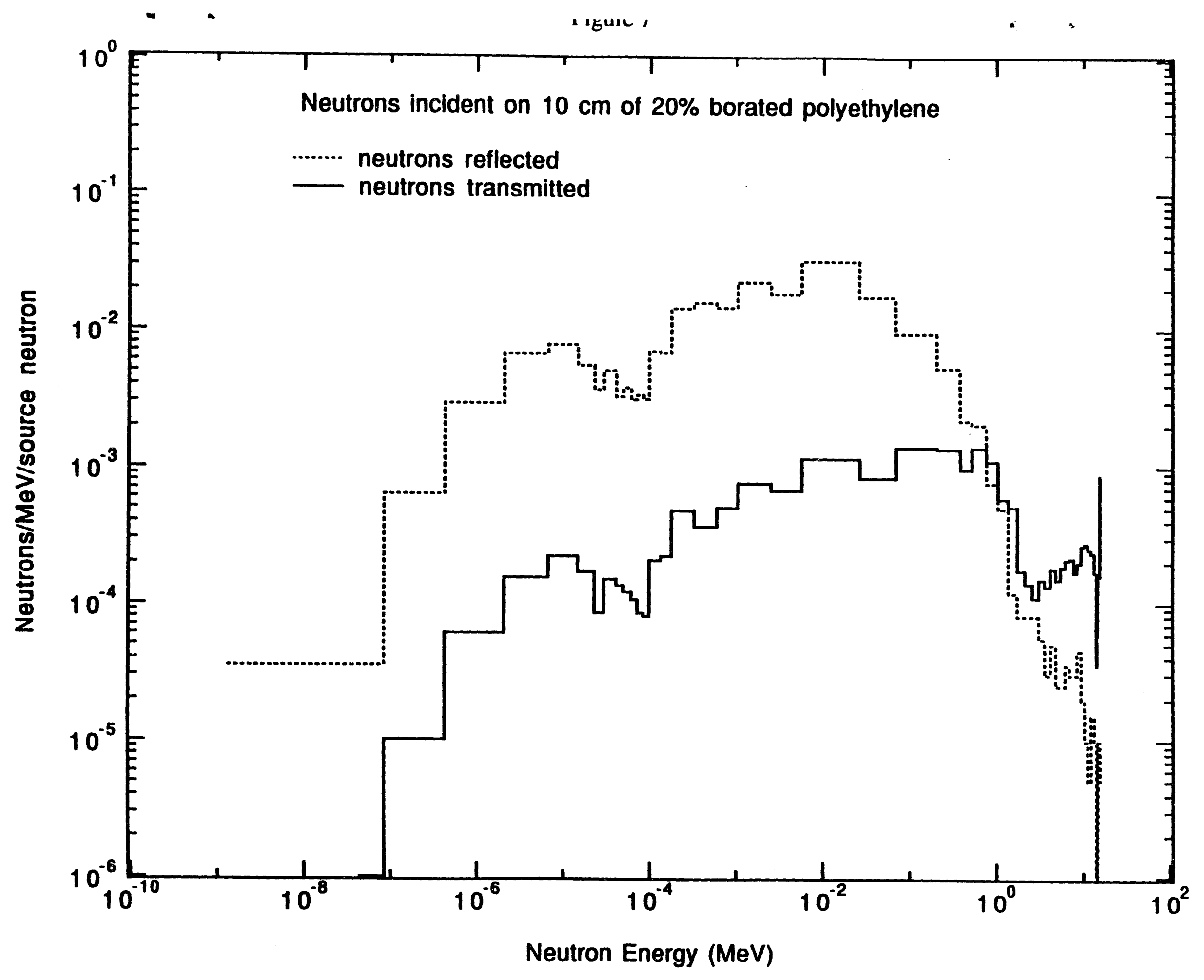



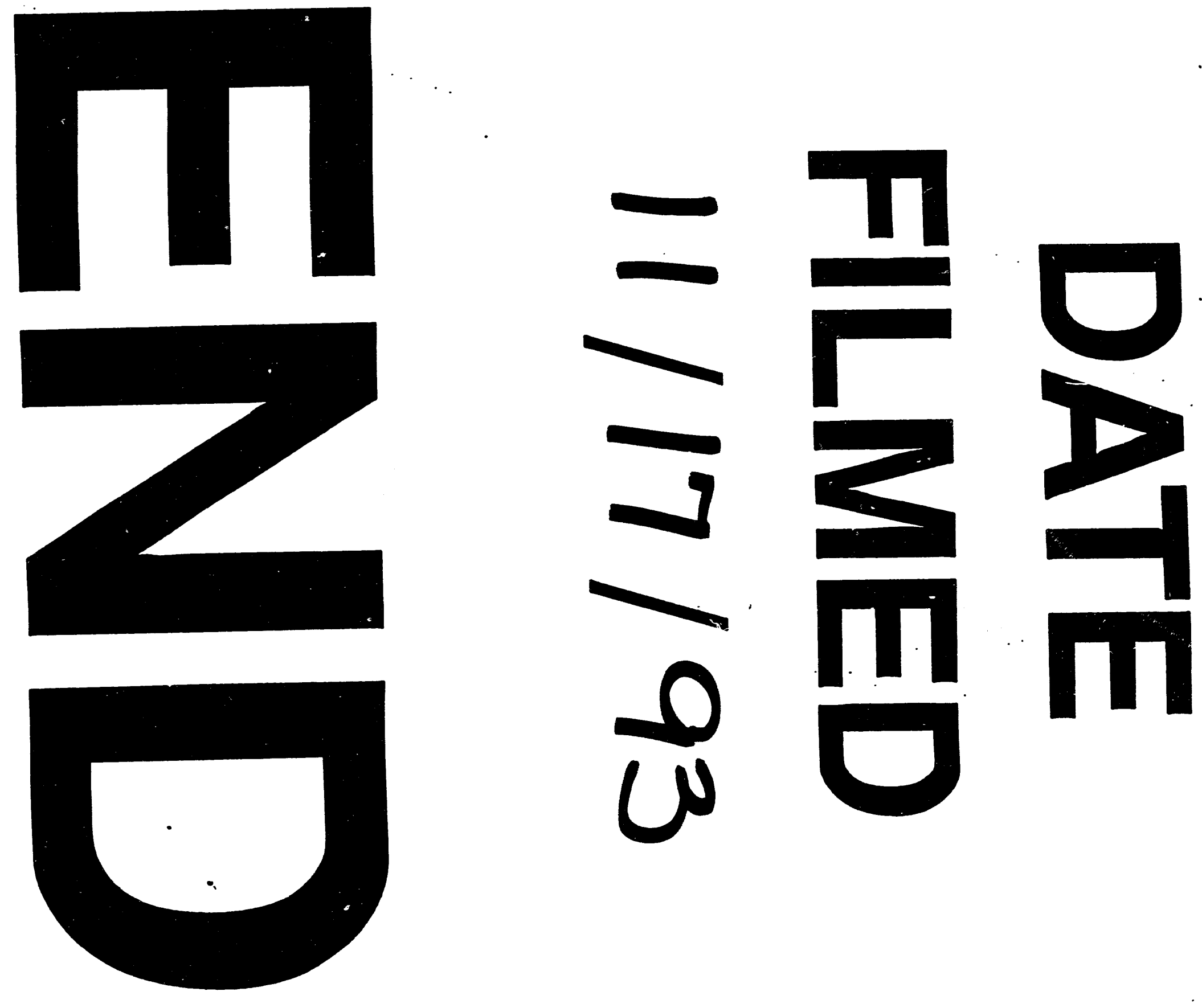


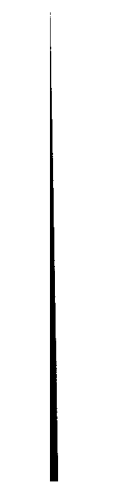

